\title{
Endoscopy-assisted distal locking of an intramedullary nail: A new experimental technique to reduce radiation exposure during distal locking of the intramedullary nails
}

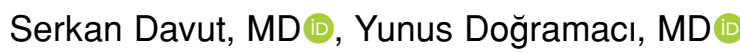 \\ Department of Orthopedics and Traumatology, Hatay Mustafa Kemal University Tayfur Ata Sökmen Faculty of Medicine, Antakya, Hatay, Turkey
}

For the last five decades, the standard treatment for lower extremity long bone shaft fractures is the intramedullary nailing in which a stable fixation can be achieved by locking the intramedullary nail proximally and distally with screws. When a targeting device is used, the distal locking usually fails due to the deforming forces in the nails. ${ }^{[1-3]}$

The most common problems are improper insertion of distal locking screws, greater exposure to radiation, and prolonged surgery duration. On the other hand, all unsuccessful attempts for the distal locking step lead to implantation failure due to the increased radiation exposure, soft tissue trauma and bone weakening due to cortical bone injury after re-drilling attempts and repeated drill to nail contact problems. ${ }^{[4,5]}$ Therefore, distal locking step becomes the main part of the intramedullary

Received: June 09, 2021

Accepted: July 28, 2021

Published online: November 19, 2021

Correspondence: Serkan Davut, MD. Hatay Mustafa Kemal Üniversitesi Tayfur Ata Sökmen Tıp Fakültesi Ortopedi ve

Travmatoloji Anabilim Dalı, 31001 Alahan Köyü, Antakya, Antakya, Hatay, Türkiye.

E-mail: serkandavul@gmail.com

Doi: $10.52312 /$ jdrs.2021.297

Citation: Davut S, Doğramacı Y. Endoscopy-assisted distal locking of an intramedullary nail: A new experimental technique to reduce radiation exposure during distal locking of the intramedullary nails. Jt Dis Relat Surg 2021;32(3):642-648.

\section{(C2021 All right reserved by the Turkish Joint Diseases Foundation}

This is an open access article under the terms of the Creative Commons Attribution-NonCommercial License, which permits use, distribution and reproduction in any medium, provided the original work is properly cited and is not used for commercial purposes (http://creativecommons.org/licenses/by-nc/4.0/).

\section{ABSTRACT}

Objectives: In this study, we aimed to introduce a new technique in which distal locking step was easier and safer for orthopedic trauma surgeons involving in the treatment of long bone fractures using an intranail endoscopic visualization and illumination method.

Materials and methods: A total of 20 fresh bovine hind limbs derived from healthy adults and killed for sale were dissected to obtain tibial bones. Two equal groups including 10 samples in each were prepared. We applied a standard nailing process in both groups: the study group $(\mathrm{n}=10)$ was locked by the new technique, intranail endoscopic illumination guidance and intranail visualization assistance locking technique and the control group $(n=10)$ was locked by the classical free-hand fluoroscopic guidance technique. We measured the surgical period time and the radiation exposure time required for the distal locking in both groups.

Results: The radiation exposure time was statistically significantly lower in the study group compared to the control group. Also, the time period required for distal locking in the study group were statistically significantly lower than the control group. With the use of the intranail endoscopic illumination guidance and visualization assistance technique, the median period time required for the distal locking procedure reduced from 477.5 to $223.5 \mathrm{sec}(\mathrm{p}<0.001)$. The median time for radiation exposure dramatically reduced from 13.5 to $2 \mathrm{sec}(\mathrm{p}<0.001)$. The median attempt number reduced from 6.5 to 2 times $(p<0.001)$.

Conclusion: This experimental study indicates that the endoscopic illumination and intranail visualization assistance technique can reduce the radiation exposure time and the period time required for distal locking compared to the free-hand fluoroscopic guidance.

Keywords: Distal locking, intramedullary nailing, orthopedic trauma, radiation exposure.

nailing procedure. Surgeons have attempted to find a safe solution, as the free-hand distal locking technique has become the most commonly preferred technique for distal locking using a C-arm X-ray 
device. Although some modifications or tricks can be made or tools can used with the C-arm, none of them guarantee to make the team and patient safe from the radiation..$^{[6,7]}$

To the best of our knowledge, the malignancy risk of the orthopedic surgery team increases with the ionizing radiation. This risk is thought to be related to the total ionizing radiation received in fluoroscopy used in all surgeries. Barry ${ }^{[8]}$ reported that the cancer risk of orthopedic surgeons increased by five times compared to the general population. Singer ${ }^{[9]}$ reported the malignancies as solid organ, skin, and hematopoietic cancers among surgeons and Chou et al. ${ }^{[10]}$ reported that the prevalence of breast cancer and all types of cancer was 2.88 and 1.9 , respectively.

Although there are several methods and devices used worldwide for distal locking to avoid the ionizing radiation exposure, only the free-hand technique remains the commonly used technique. ${ }^{[3,11-17]}$

Since the first endoscopic device, namely gasogene cystoscope was invented by Désormeaux ${ }^{[18]}$ in the 1850s, technological developments have followed each other with the curiosity and desire to research. Currently, endoscopy has become an indispensable part of minimally invasive surgery in the field of orthopedics and traumatology, as in many surgical branches. In our practice, rigid arthroscopes are the main preferred devices, particularly in joint surgeries and other endoscopic treatments such as discectomy, carpal tunnel syndrome surgery, or tendon repair surgeries. However, flexible endoscopes which are the main devices of laparoscopic surgeries do not have enough functionality in the practice of orthopedics. Superior diagnostic competence, low morbidity, low complication rates, short hospital stay, and early recovery are the major advantages of endoscopic surgeries. ${ }^{[19]}$ These advantages make surgeons attempt to utilize endoscopy in their treatment strategies and surgical technique developments.

In the present study, we aimed to introduce a new technique in which distal locking step was easier and safer for orthopedic trauma surgeons involving in the treatment of long bone fractures.

\section{MATERIALS AND METHODS}

A total of 20 fresh bovine hind limbs were dissected to obtain tibial bones. The bovines (average age 12 to 14 months) were all derived from healthy adults and were killed for sale. All bone specimens had approximately similar dimensions regarding the bone length and canal diameter. The tibial bones were removed from fresh limbs and kept moist in saline solutions during preparations, and tests were performed on the same day. The specimens were randomly placed into two equal groups for intramedullary nailing. We applied a standard tibial intramedullary nail (Manyetix ${ }^{\circledR}$, IMD Medical Products Ltd., Istanbul, Turkey) and standard intramedullary nailing process in both groups: the study group $(n=10)$ was locked by the new technique, intranail endoscopic illumination guidance and intranail visualization assistance locking technique and the control group $(n=10)$ was locked by the classical free-hand fluoroscopic guidance technique. We applied a standard intramedullary nailing procedure for the entry point and the insertion of the nail. However, we modified the distal locking technique in the study group using the same nail implementation set, but locking by the endoscopic illumination guidance and intranail visualization assistance. An endoscopic camera for visualization and a bright, intense light source for illumination made by using a flexible endoscope (ENTity ${ }^{\mathrm{TM}}$ SDXL , Optim LLC, MA, USA) was used (Figure 1). Operating

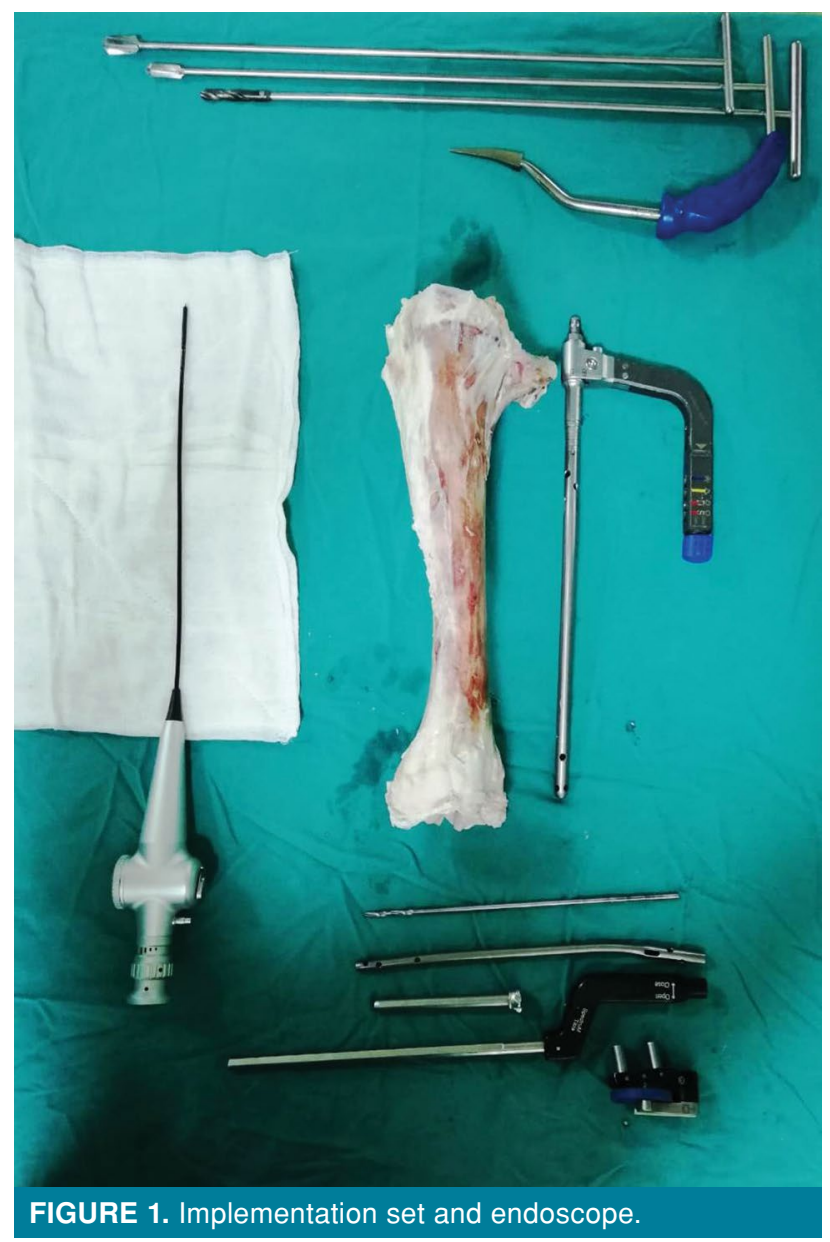


room set-up was used based on a flexible endoscope (with its own light source) that can be connected to arthroscopic viewing system. A flexible endoscope was preferred, as it was easily adapted to the curved structure of the tibial nail. The outer diameter of the endoscope was $2.7 \mathrm{~mm}$. The nail had a cannula diameter of $4 \mathrm{~mm}$ and the nail connector tool had a cannula diameter of $3.5 \mathrm{~mm}$. The flexible endoscope was easily engaging inside the connector and the nail canal. The endoscope had an articulation range of 110 degrees with a field of view of 85 degrees. Also, the endoscope with light-emitting diode (LED) system was providing a vibrant white light targeted
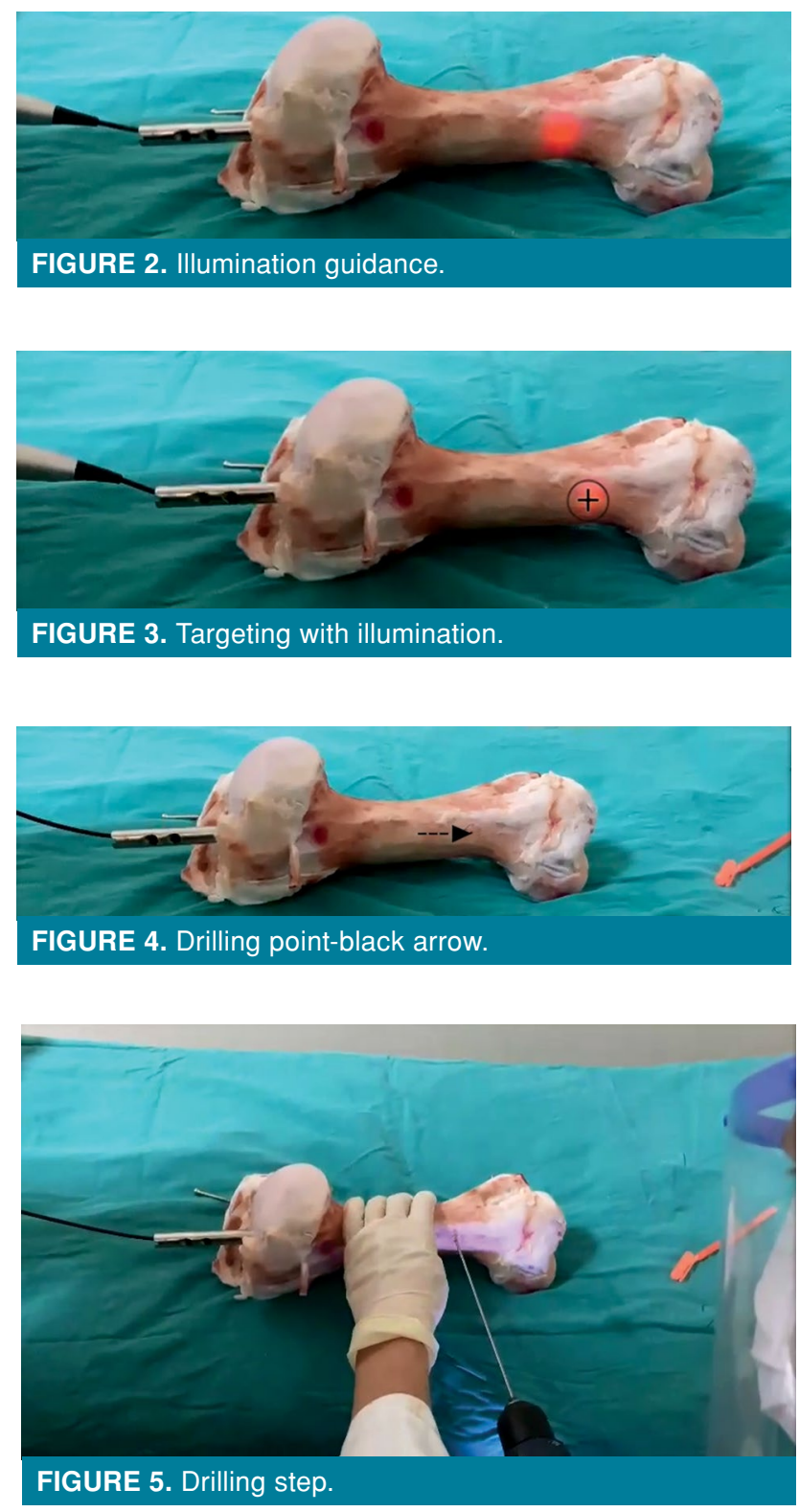

in the $5500 \mathrm{~K}$ color temperature range for clear illumination.

After intramedullary nail insertion, the endoscope was inserted inside the nail and the room light brightness decreased by 30\% (not was necessary, but for optimal illumination) to visualize the hole reflection site of the distal locking by the light applied through the tunnel (Figure 2). In some specimens, maximum of $50 \mathrm{~mL} 0.9 \%$ saline irrigation was provided and aspiration (with $\mathrm{ch} / \mathrm{fr} 8$ suction catheter) was performed to achieve a clear vision. The distal locking hole was targeted through the illumination which was visible through the cortices (Figure 3). This inside-out illumination technique guidance was fairly enough for exactly targeting the locking point (Figure 4). The center of the visualized light was our drilling point (Figure 5). The passing
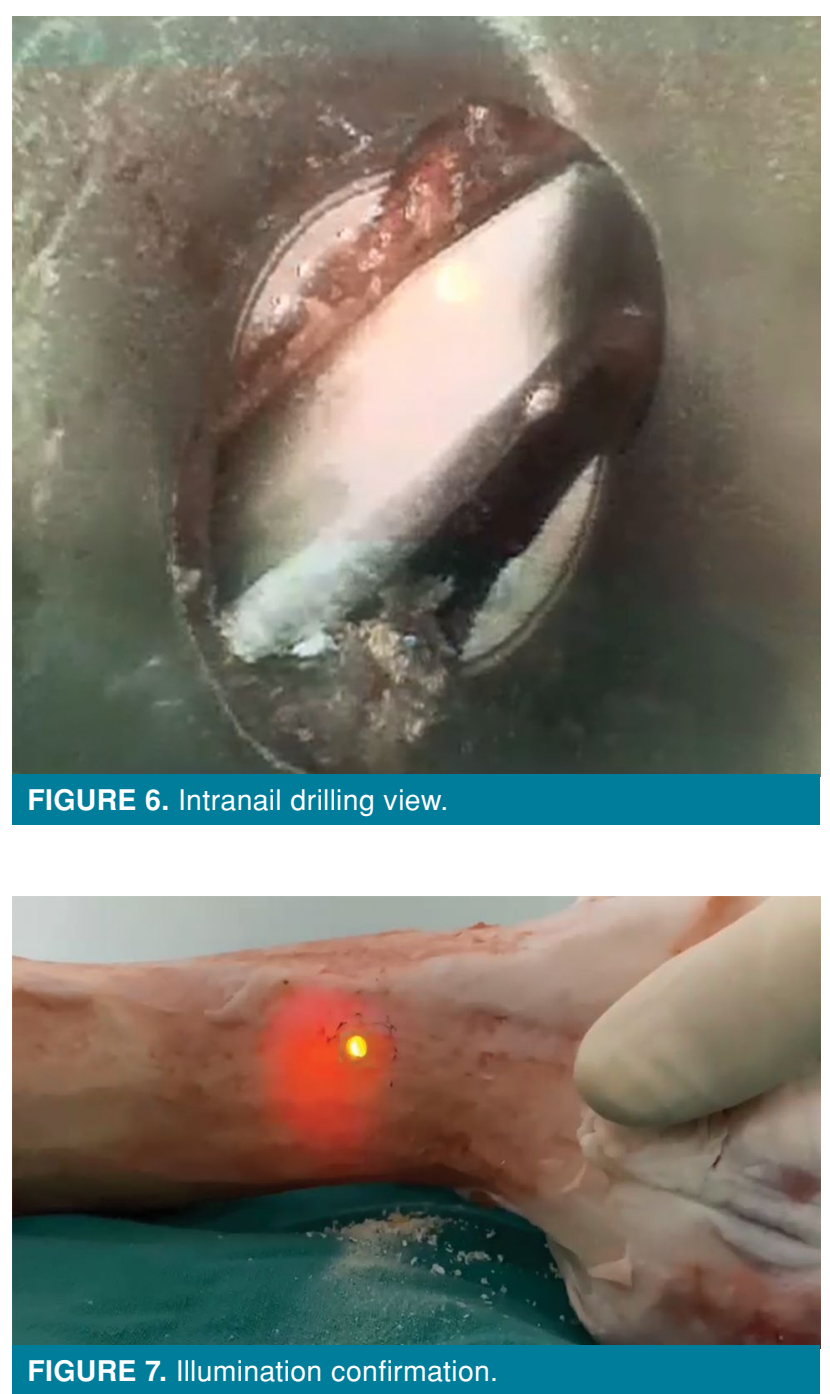
drill was visualized endoscopically through the distal hole which made the distal locking more precise (Figure 6). In addition, the correlation was made by observing the clear light seen outer the bone through the drilling hole (Figure 7, Video 1).

In the study group, the locking step was made by the light guidance and confirmed by intranail visualization. The fluoroscopy was only used at the end of the procedure to authenticate the screw position with the anteroposterior (Figure 8 ) and lateral fluoroscopic views (Figure 9). In the control group, fluoroscopic guidance was used throughout the distal
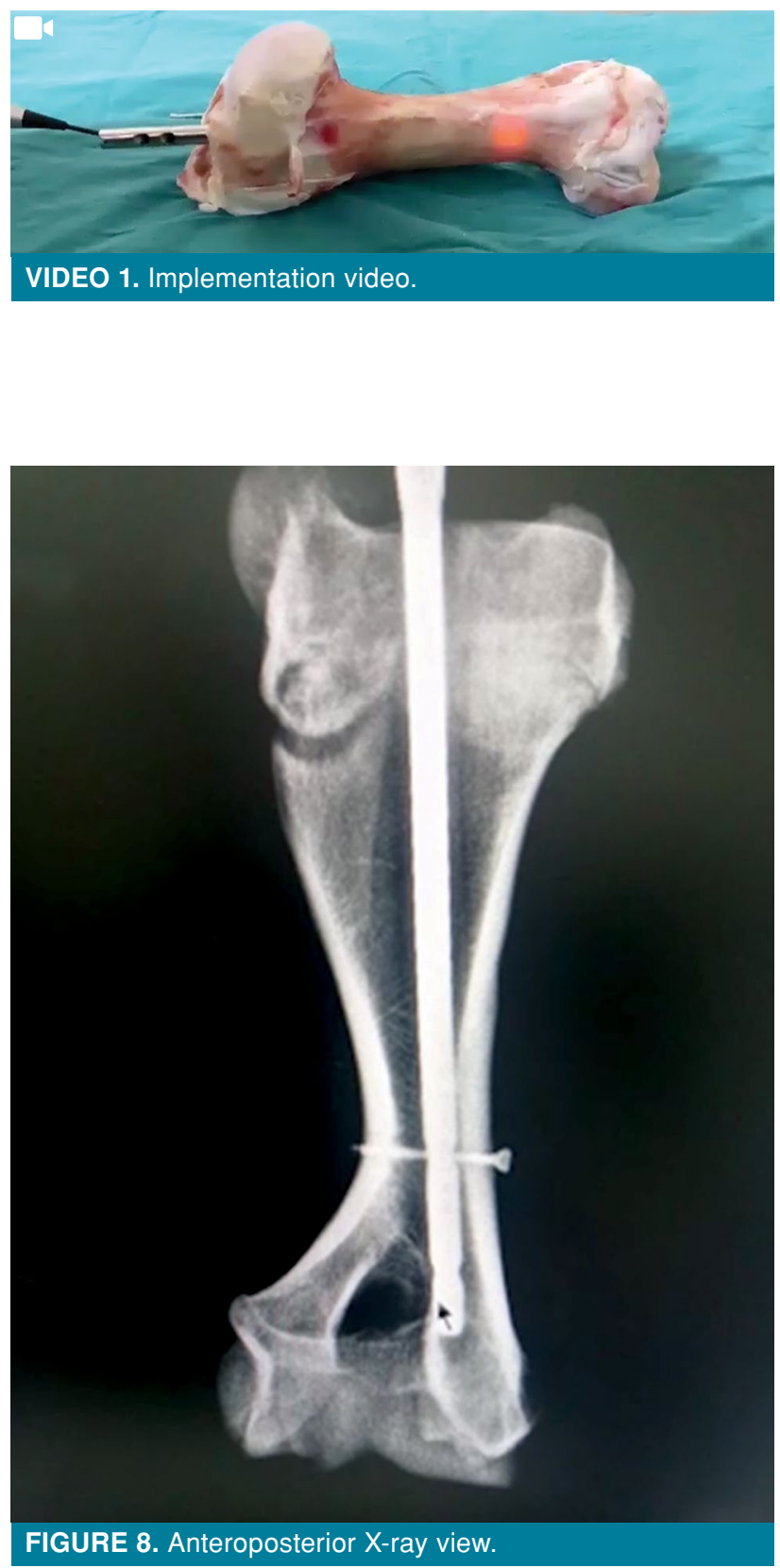

locking process. In both groups, we measured the time period required for distal locking (sec), the radiation exposure time used for the distal locking (sec), and the number of attempts for a successful locking.

\section{Statistical analysis}

Statistical analysis was performed using the SPSS version 18.0 software (SPSS Inc., Chicago, IL, USA). The distribution of the data in the groups was examined according to the Shapiro-Wilk test. Data that did not show normal distribution were compared with the Mann-Whitney U test. Numerical data were given as median (min-max). $\mathrm{P}<0.05$ was considered significant.

\section{RESULTS}

The application data for each sample are shown in Table I. In the study group, the median time for distal interlocking was 223.5 seconds, ranging from 156 to 267 seconds. The median fluoroscopy time during distal interlocking was 2 sec. to document

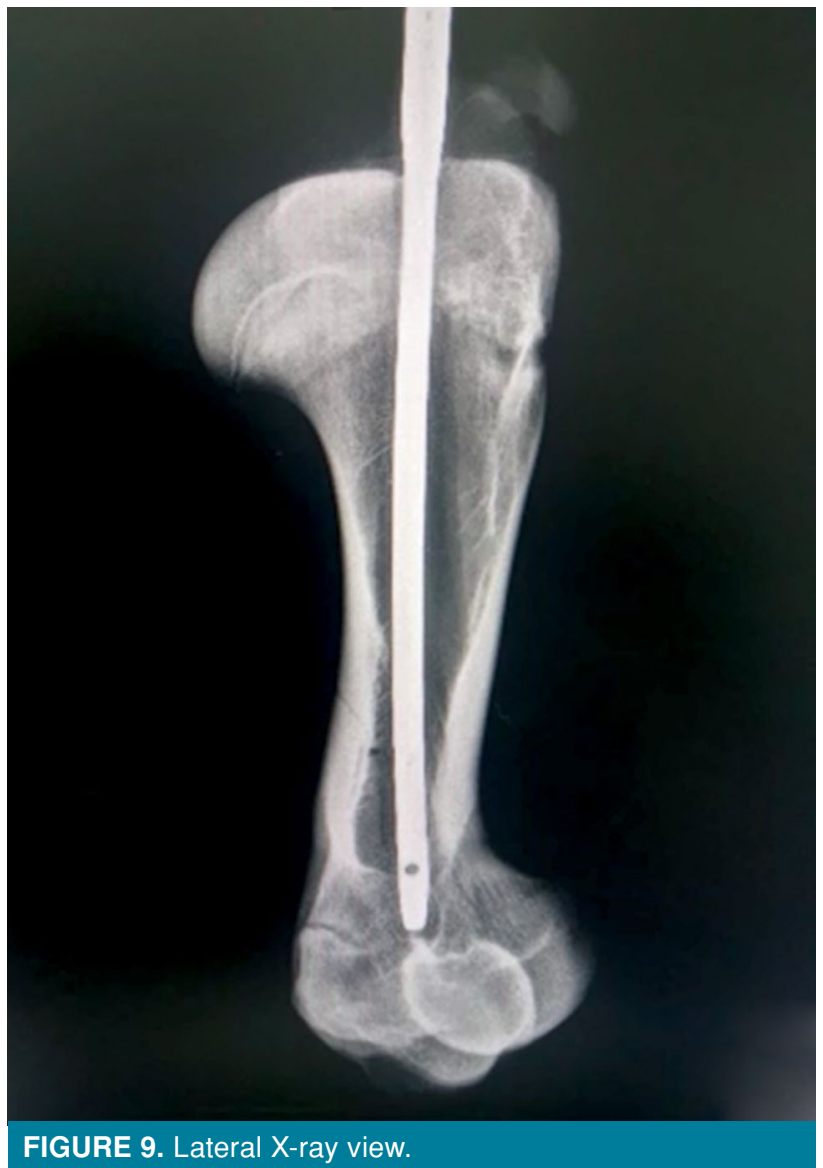




\begin{tabular}{|c|c|c|c|c|c|c|}
\hline \multirow[b]{4}{*}{ Sample } & \multicolumn{6}{|c|}{$\begin{array}{c}\text { TABLE I } \\
\text { Variable scores }\end{array}$} \\
\hline & \multicolumn{6}{|c|}{ Variable scores } \\
\hline & \multicolumn{3}{|c|}{ Study Group } & \multicolumn{3}{|c|}{ Control Group } \\
\hline & $\begin{array}{l}\text { Distal locking } \\
\text { time (sec.) }\end{array}$ & $\begin{array}{l}\text { Floroscopy } \\
\text { time (sec.) }\end{array}$ & Total attempt number & $\begin{array}{l}\text { Distal locking } \\
\text { time (sec.) }\end{array}$ & $\begin{array}{l}\text { Floroscopy } \\
\text { time (sec.) }\end{array}$ & $\begin{array}{c}\text { Total attempt number } \\
\text { (Redrilling/redirection attempt) }\end{array}$ \\
\hline 1 & 233 & 2 & 2 & 410 & 12 & $6(1 / 3)$ \\
\hline 2 & 252 & 2 & 2 & 523 & 9 & $5(1 / 2)$ \\
\hline 3 & 267 & 2 & 2 & 395 & 16 & $8(3 / 3)$ \\
\hline 4 & 264 & 2 & 2 & 612 & 19 & $9(2 / 5)$ \\
\hline 5 & 243 & 2 & 2 & 356 & 11 & $6(2 / 2)$ \\
\hline 6 & 214 & 2 & 2 & 466 & 15 & 7 (3/2) \\
\hline 7 & 186 & 2 & 2 & 532 & 16 & $8(2 / 4)$ \\
\hline 8 & 211 & 2 & 2 & 489 & 12 & $6(2 / 2)$ \\
\hline 9 & 199 & 2 & 2 & 421 & 8 & $4(1 / 1)$ \\
\hline 10 & 156 & 2 & 2 & 495 & 15 & $7(2 / 3)$ \\
\hline
\end{tabular}

\begin{tabular}{|c|c|c|c|c|c|c|c|c|}
\hline & & & Statist & $\begin{array}{l}\text { BLE II } \\
\text { analysis }\end{array}$ & & & & \\
\hline & & Distal & duration (sec) & Radiatic & ration (sec) & Atter & number & \\
\hline Groups & $n$ & Median & Min-Max & Median & Min-Max & Median & Min-Max & $p$ \\
\hline Study group & 10 & 223.5 & $156-267$ & 2 & $2-2$ & 2 & $2-2$ & $<0.001$ \\
\hline Control group & 10 & 477.5 & $356-612$ & 13.5 & 8-19 & 6.5 & $4-9$ & $<0.001$ \\
\hline
\end{tabular}

the locking step by two X-ray images. All samples were targeted and drilled at the first attempt and redirection of the drill made by the visual assistance to avoid drill to nail contact when necessary.

In the control group, the median time for distal interlocking was $477.5 \mathrm{sec}$, ranging from 356 to $612 \mathrm{sec}$. The median fluoroscopy time during distal interlocking was 13.5 ranging from 8 to 19 sec. The median attempt number of distal interlocking (For both holes) was 6.5 ranging from 4 to 9 including additional redrilling and/or redirection attempts.

Distal locking period time, fluoroscopy time, and attempt number were statistically significantly reduced in the study group compared to the control group ( $\mathrm{p}<0.001)$ (Table II).

\section{DISCUSSION}

The present study showed that endoscopic visualization and illumination technique made the distal locking step safer and easier by reducing the distal locking period time and the fluoroscopy time required to insert distal interlocking screws. ${ }^{[20]}$ Furthermore, we found that our technique reduced the drill misplacement rate and multiple drilling attempt rates, which are the main cause of unnecessary bone and soft tissue complications and the increased fluoroscopy time.

To the best of our knowledge, this is the first experimental study to use the endoscopy technique to facilitate the distal locking step of the intramedullary nailing procedure. It has been proven that the freehand technique decreases the distal locking time and the radiation exposure time, compared to the aiming devices which may end with multiple misdrilling attempts. ${ }^{[4,5]}$ Veen et al. ${ }^{[21]}$ reported 30 cases treated with a distal aiming device in which 16 needed fluoroscopy. They concluded that the use of an aiming device for distal locking of a tibia nail could prolong, but not reduce, the operation time. Gugala et al. ${ }^{[22]}$ also reported that a distal targeting device could significantly decrease $(\sim 60 \%)$ the mean fluoroscopy time necessary to complete distal interlocking versus free-hand technique; however, surgery time and distal locking time remained unchanged. In our study, we found that both intramedullary illumination and intranail visualization technique reduced the distal 
locking time and the fluoroscopy time to $53.2 \%$ and $85.2 \%$, respectively compared to the free-hand technique.

According to the literature, personal experience of the surgeon with the free-hand technique affects the radiation exposure dose and the surgery time. ${ }^{[14,23-27]}$ Kirousis et al. ${ }^{[23]}$ reported 25 cases treated with free-hand technique and they concluded that the primary surgeon was at a higher risk and the operation team must take care of radiation dose optimization. In our study, the radiation exposure was minimized and there was a short learning curve required for successful locking the holes using the new technique.

With light-assisted illumination guidance and intranail visualization assistance method, drill to nail contact problems and misdrilling complications occurring in the soft tissue and bone cortex can be prevented by reducing the number of drilling attempts. Anastopoulos et al. ${ }^{[28]}$ reported 63 patients treated with a distal targeting device with failure in two cases and also medial cortex penetration in other the three cases. In the control group, the higher attempt number rates resulted from multiple redrilling and/or redirection attempts. The advantage of the new technique locates the exact drilling point with illumination guidance and avoids drill to nail contact with visualization assistance. Therefore, we had no failure of distal locking attempt with the endoscopic device in our study.

One of the limitations of this study is the use of bovine tibial bones, instead of human bones or cadaveric specimens. The bovine bones may differ in structural quality from those of the human; they are larger in all dimensions and have thicker bony cortex than human bones. This is an advantage for our study and we consider that the light guidance seen out of the bone would be much more accurate, if used with the human specimens or in vivo tests. Overall, bovine bones were used in previous experimental studies and in the reports, and the authors reported that bovine bones had the same structural quality as human bones. ${ }^{[29,30]}$ Another limitation is the absence of the soft tissue envelope on the bones. In our early experiments with samples, including the soft tissue envelope on the bone, illumination failed which was probably due to the power of the light source of the endoscope. However, we observed that when a skin incision of approximately $4 \mathrm{~cm}$ was made, which was dissected up to the bone surface, illumination could be seen on the bone. Therefore, we performed a study without soft tissue to provide better visualization of the illumination on the bone. An additional limitation is that we designed an experimental process without creating a fracture and, therefore, the effect of fracture was not taken into consideration. Also, although no significant bleeding or fog occurred during our practices, intraluminal bleeding in living beings may be an important limitation. In this case, it is thought that tourniquet application, saline irrigation or continuous aspiration may be beneficial to avoid excessive irrigation and prevent potential soft tissue fluid extravasation. Furthermore, these results should be supported by in vivo studies with the aforementioned details. Currently, a recent prospective cooperative study is ongoing in our clinic regarding the in vivo application of the illumination guidance and visualization assistance of distal locking.

In conclusion, this experimental study indicates that the endoscopic illumination and intranail visualization assistance technique can reduce the radiation exposure time and the period time required for distal locking compared to the free-hand fluoroscopic guidance.

\section{Declaration of conflicting interests}

The authors declared no conflicts of interest with respect to the authorship and/or publication of this article.

\section{Funding}

The authors received no financial support for the research and/or authorship of this article.

\section{REFERENCES}

1. Krettek C, Mannss J, Miclau T, Schandelmaier P, Linnemann I, Tscherne H. Deformation of femoral nails with intramedullary insertion. J Orthop Res 1998;16:572-5.

2. Hutson JJ, Zych GA, Cole JD, Johnson KD, Ostermann P, Milne EL, et al. Mechanical failures of intramedullary tibial nails applied without reaming. Clin Orthop Relat Res 1995;315:129-37.

3. Krettek C, Könemann B, Miclau T, Schlandelmaier P, Blauth $\mathrm{M}$, Tscherne $\mathrm{H}$. In vitro and in vivo radiomorphometric analyses of distal screw hole position of the solid tibial nail following insertion. Clin Biomech (Bristol, Avon) 1997;12:198-200.

4. Knudsen CJ, Grobler GP, Close RE. Inserting the distal screws in a locked femoral nail. J Bone Joint Surg [Br] 1991;73:660-1.

5. Mitchell PM, Collinge CA, Barcak E, Perez E, Triantafillou K. Proximity and risks of the anterior neurovascular and tendinous anatomy of the distal leg relative to anteriorly applied distal locking screws for tibia nailing: A plea for open insertion. J Orthop Trauma 2017;31:375-9.

6. Tsalafoutas IA, Tsapaki V, Kaliakmanis A, Pneumaticos S, Tsoronis F, Koulentianos ED, et al. Estimation of radiation doses to patients and surgeons from various fluoroscopically guided orthopaedic surgeries. Radiat Prot Dosimetry 2008;128:112-9. 
7. Kwong LM, Johanson PH, Zinar DM, Lenihan MR, Herman MW. Shielding of the patient's gonads during intramedullary interlocking femoral nailing. J Bone Joint Surg [Am] 1990;72:1523-6.

8. Barry TP. Radiation exposure to an orthopedic surgeon. Clin Orthop Relat Res 1984;182:160-4.

9. Singer G. Occupational radiation exposure to the surgeon. J Am Acad Orthop Surg 2005;13:69-76.

10. Chou LB, Cox CA, Tung JJ, Harris AH, Brooks-Terrell D, Sieh $W$. Prevalence of cancer in female orthopaedic surgeons in the United States. J Bone Joint Surg [Am] 2010;92:240-4.

11. Uruc V, Ozden R, Dogramacı Y, Kalacı A, Dikmen B, Yildız OS, et al. The comparison of freehand fluoroscopic guidance and electromagnetic navigation for distal locking of intramedullary implants. Injury 2013;44:863-6.

12. Windolf M, Schroeder J, Fliri L, Dicht B, Liebergall M, Richards RG. Reinforcing the role of the conventional C-arm--a novel method for simplified distal interlocking. BMC Musculoskelet Disord 2012;13:8.

13. Malek S, Phillips R, Mohsen A, Viant W, Bielby M, Sherman K. Computer assisted orthopaedic surgical system for insertion of distal locking screws in intra-medullary nails: a valid and reliable navigation system. Int J Med Robot 2005;1:34-44.

14. Ma L, Zhao Z, Zhang B, Jiang W, Fu L, Zhang X, et al. Three-dimensional augmented reality surgical navigation with hybrid optical and electromagnetic tracking for distal intramedullary nail interlocking. Int J Med Robot 2018;14:e1909.

15. Oszwald M, Westphal R, Stier R, Gaulke R, Calafi A, Müller CW, et al. Hands-on robotic distal interlocking in intramedullary nail fixation of femoral shaft fractures. Technol Health Care 2010;18:325-34.

16. Lee MY, Kuo $\mathrm{CH}$, Hung SS. A new fluoroscopy-free navigation device for distal interlocking screw placement. J Med Eng Technol 2008;32:284-95.

17. Hsu WE, Yu CH, Chang CJ, Wu DS, Yu TH, Tseng CS. Implementation and performance evaluation of a drilling assistive device for distal locking of intramedullary nails. Int J Med Robot 2020;16:e2110.

18. Jackson RW. A history of arthroscopy. Arthroscopy 2010;26:91-103.

19. Friberger Pajalic K, Turkiewicz A, Englund M. Update on the risks of complications after knee arthroscopy. BMC Musculoskelet Disord 2018;19:179.

20. Atik OŞ. Is there something new and interesting in my article? Eklem Hastalik Cerrahisi 2019;30:69.

21. Veen EJ, Ettema HB, Zuurmond RG, Mostert AK. Are there any advantages in using a distal aiming device for tibial nailing? Comparing the Centro Nailing System with the Unreamed Tibia Nail. Injury 2011;42:1049-52.

22. Gugala Z, Nana A, Lindsey RW. Tibial intramedullary nail distal interlocking screw placement: comparison of the free-hand versus distally-based targeting device techniques. Injury 2001;32 Suppl 4:SD21-5.

23. Kirousis G, Delis H, Megas P, Lambiris E, Panayiotakis G. Dosimetry during intramedullary nailing of the tibia. Acta Orthop 2009;80:568-72.

24. Langfitt MK, Halvorson JJ, Scott AT, Smith BP, Russell GB, Jinnah RH, et al. Distal locking using an electromagnetic fieldguided computer-based real-time system for orthopaedic trauma patients. J Orthop Trauma 2013;27:367-72.

25. Blattert TR, Fill UA, Kunz E, Panzer W, Weckbach A, Regulla DF. Skill dependence of radiation exposure for the orthopaedic surgeon during interlocking nailing of longbone shaft fractures: a clinical study. Arch Orthop Trauma Surg 2004;124:659-64.

26. Patra SK, Shetty AP, Jayaramaraju D, Rajasekaran S. Radiation exposure to the surgeon, surgical assistant, and scrub nurse during closed intramedullary nailing of long bones-does it vary depending on the experience of the surgeon? J Orthop Trauma 2019;33:e52-e57.

27. Tasbas BA, Yagmurlu MF, Bayrakci K, Ucaner A, Heybeli M. Which one is at risk in intraoperative fluoroscopy? Assistant surgeon or orthopaedic surgeon? Arch Orthop Trauma Surg 2003;123:242-4.

28. Anastopoulos G, Ntagiopoulos PG, Chissas D, Papaeliou A, Asimakopoulos A. Distal locking of tibial nails : A new device to reduce radiation exposure. Clin Orthop Relat Res 2008;466:216-20.

29. Fletcher JWA, Williams S, Whitehouse MR, Gill HS, Preatoni E. Juvenile bovine bone is an appropriate surrogate for normal and reduced density human bone in biomechanical testing: a validation study. Sci Rep 2018;8:10181.

30. Predrag G, Milorad M, Milan M, Milan G. Comparison of biomechanical stability of osteosynthesis materials in long bone fractures. Med Glas (Zenica) 2019;1:88-92. 